\title{
Developing the Indicators of e-Decision Making Competence for College Students
}

\author{
Pi-Shan Hsu, a , Te-Jeng Chang ${ }^{2, b}$ and Joni Tzuchen Tang ${ }^{3, c}$ \\ ${ }^{1}$ Ching Kuo Institute of Management and Health, 336 Fushing Road, Keelung, Taiwan \\ ${ }^{2} 6$ F-8, 257, Ren-Yi Road, Keelung, Taiwan \\ ${ }^{3}$ No.134, Sec. 2, Heping E. Rd., Taipei, Taiwan \\ aivymax950@yahoo.com.tw, btjmax950@yahoo.com.tw (corresponding author), \\ cjttang0@gmail.com
}

Keywords: e-decision making, competence, indicator

\begin{abstract}
The decision-making competence has become the inevitable tendency in information communication technology. Schools today focus on how to raise student's e-decision making competence. The purposes of this research are (1) to define the e-decision making competence of students major in computer science should attain; (2) to establish the indicators of e-decision making competence. The indicator content of e-decision making competence is identified through literature review. Then the Hermeneutics methodology is applied to construct the indicators. The finding indicates that indicators include seven competences in terms of information definition, information access, information assessment, information management, information conformity, information innovation and information dissemination.
\end{abstract}

\section{Introduction}

Global economics' impetus relies on unceasingly digital system. The assessment and the demonstration of information communication technology (ICT) is the developmental priority in many higher and adult educational programs. Within the IT's explosion period, the communication science and technology had made a huge progress, and application of communication science and technology, which carries on the decision-making, the problem analysis, and the solution, has become the inevitable tendency in ICT world [1,2].

However, the quality assurance of decision making becomes a major issue. For example, students may have ability to operate information, technology, and computer, but they cannot process their competence of logic analysis and problem-thinking, to make "high efficiency" and "high quality" decision.

e-decision making competence refers to critical thinking, the analysis/solution of problems, and the operation/assistant of information and e-systems [3,4]. Students gradually internalize and summarize their e-decision making competences into their actions and values of self-motivated and self-decision. That means students are able to process their logic and problem-solving skills to make a correct and appropriated decision in technology-usage. Therefore, the main target of school today should focus on how to raise student's e-decision making competence.

The authors conduct literature analysis to identify the indicator content of e-decision making competence in order to develop the draft indicators of e-decision making competence. The purposes of this research are (1) to define the e-decision making competence of students major in computer science should attain; (2) to establish the indicators of e-decision making competence. 


\section{Literature Review}

Problem Solving. Problem solving is a combinational plan, whereas students use the knowledge and concepts they already learned to solve the problems and issues [5]. Problem solving is a kind of learning process [6]. During this process, individual goes through the past experiences and the skills/knowledge already learned to understand, analyze, and evaluate the question. When the problem is being solved, students accumulate and promote self-ability performance unceasingly. Problem solving can be considered as a process of mental training [7]. In order to solve the problem and meet the desire, individual use his/her own knowledge, experiences, skills, and thinking. The mental training grows when individual deals with difficult situation and still knows the ways and functions to seek help to solve the problems. Problem solving competences, which include finding problems, analyzing currency, making right decision, implementing projects, and evaluating the conclusion, all should be categorized in higher thinking process [8]. In summary, problem solving includes defining question, solving question, and evaluating conclusion, which is a thinking process constructed by individual experiences and background.

Information Literacy. "Information literacy" appeared in the 1974's conference of United States National Commission on Libraries and Information Science, NCLIS. At that time, president Zurkowski, the President of American Information Industrial Association, proposed this term "Information literacy" by the first time. In 21 st century, the information literacy extends its meaning for "information competency" or "information skills", and transfers into higher knowledge, skills, and attitudes. In this case, "information literacy" is no longer just a technology and computer cognition. It presents the progress how individual reads and develops technology.

e-Decision Making. The competence of e-decision making refers to students' problem solving and information literacy $[3,4]$. The concept mapping of e-decision making competence is referred to Fig. 1.

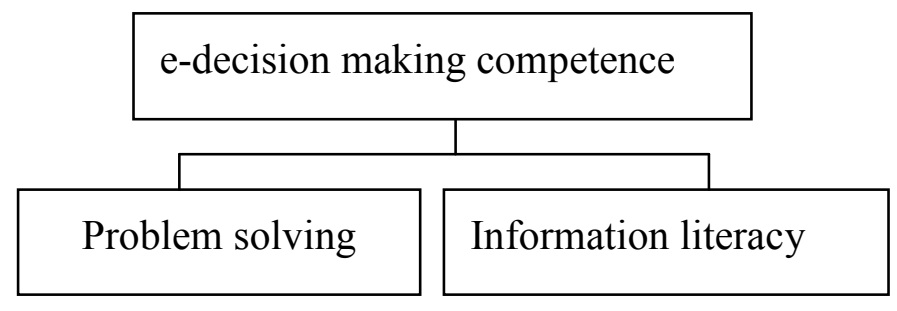

Fig 1. The concept mapping of e-decision making competence

\section{Method}

In this study, Hermeneutics methodology is applied to construct the indicators of e-decision making competence. Representative decisive indicators are mainly developed by unceasing construction and explanation through Hermeneutics methodology [9].

Expert Groups. All involved experts are arranged into two groups in terms of academic specialized group and business specialized group. The academic specialized group is organized by professors; the business specialized group is organized by business experts. Please refer to Table 1 and Table 2 for the details of expert groups.

Table 1. Academic specialized group

\begin{tabular}{llll}
\hline No. & Gender & \multicolumn{1}{c}{ Department } & Years of service \\
\hline 1 & Male & Applied Electronics & Over 26 \\
2 & Male & Applied Electronics & $16-20$ \\
3 & Male & Information Communication & Under 5 \\
4 & Male & Information Communication & $6-10$ \\
\hline
\end{tabular}


Table 2. Business specialized group

\begin{tabular}{lllll}
\hline No. & Gender & \multicolumn{1}{c}{ Title } & \multicolumn{1}{c}{ Business } & \multicolumn{1}{c}{ Years of service } \\
\hline 1 & Male & Manager & College & Under 5 \\
2 & Female & Executive & Information business & Under 5 \\
3 & Male & Director & Information business & $16-20$ \\
4 & Male & Manager & Taipei Bureau of Education & Over 20 \\
\hline
\end{tabular}

Hermeneutics Process. According to the Hermeneutics methodology, the indicators are developed in following three steps:

- Step 1: By applying literature review, the indicator content of e-decision making competence is identified.

- Step 2: By constructing two expert groups and applying Hermeneutics methodology, the draft e-decision making indicators are developed until the consensuses are made by the academic specialized group.

- Step 3: The draft e-decision making indicators are revised and turned into final version of indicators until the consensuses are made by the business specialized group.

During the Hermeneutics process, each indicator will be analyzed to follow the reliability and validity of research. The Hermeneutics process is presented in Fig. 2.

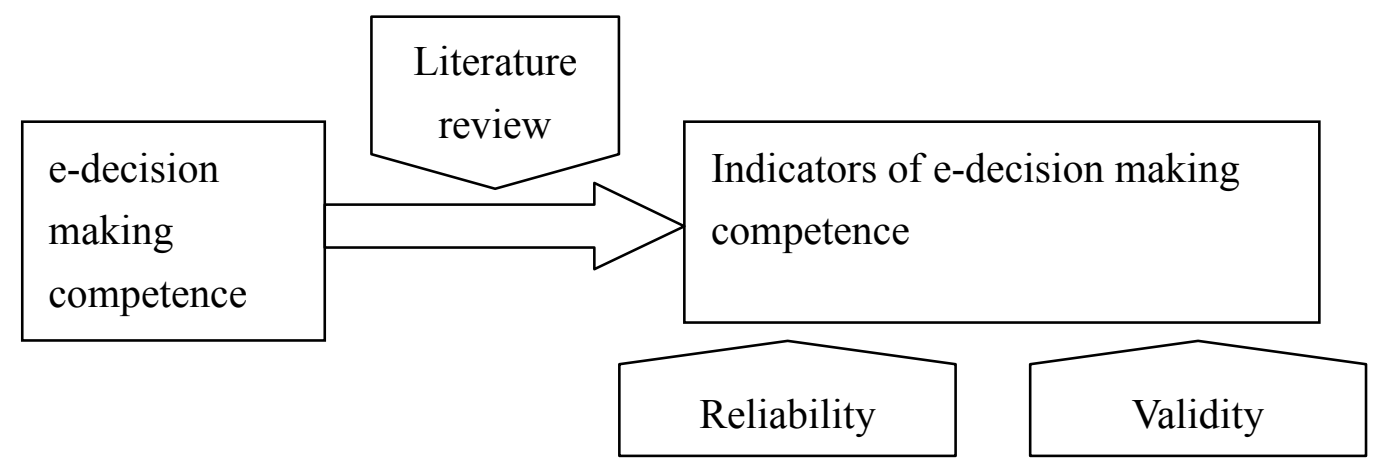

Fig 2. Hermeneutics process.

\section{Data Analysis}

94 indicators are categorized into seven competences in terms of information definition, information access, information assessment, information management, information conformity, information innovation and information dissemination. Two expert groups grade those 94 indicators according to the level of importance by using 5-point Likert scales. Then two sets of rating scores are obtained, and the consistence analysis is conducted on those two sets of rating scores by SPSS statistics software. Based on the Kendall coefficient received by the consistence analysis, two groups of experts' opinions from two expert groups reach the consistent level. And the chi-square tests indicate that the consistent exam reaches the level of significance $(p<.05)$.

According to the data, academic specialized group agrees there are 94 indicators reach the levels of "very important"; none indicator has reach the level of "important" and "average". Whereas, business specialized group agrees there are 74 indicators reach the level of "very important", 20 for level of "important", and 0 for level of "average".

Referring to Table 3, both expert groups agree there are 74 indicators reach the level of "very important", none for the level of "important". Therefore, 74 indicators are developed for e-decision making competence. The rate of consistent has reached $78.72 \%$. 
Table 3. Crosstabs analyzing of academic and business specialized groups

\begin{tabular}{cccccc}
\hline & & \multicolumn{4}{c}{ Academic Specialized Group } \\
& importance & 3 & 4 & 5 & Total \\
\hline \multirow{2}{*}{ Business Specialized } & 3 & 0 & 0 & 0 & 0 \\
Group & 4 & 0 & 0 & 20 & 20 \\
& 5 & 0 & 0 & 74 & 74 \\
\hline & Total & 0 & 0 & 94 & 94 \\
\hline
\end{tabular}

consistent ratio $P=\frac{74}{94}=78.72(\%)$

Kendall coefficient of concordance equals $.641, \chi_{(93)}^{2}=297.840, p<.001$. It reaches the level of significance (refer to Table 4). The numbers shows the indicators have reached the consistent, and the reliability of each expert has reached the superior level.

Table 4. Consistent exam of expert groups

\begin{tabular}{cccc}
\hline Kendall's $W$ & $\chi^{2}$ & $d f$ & $p$ \\
\hline .641 & 297.840 & 93 & .000 \\
\hline
\end{tabular}

\section{Conclusions}

This research focuses on developing indicators of e-decision making competence. The authors believe the information of teachings and contents can be variable, but the different teaching and contents follow the same pattern of indicators. Therefore, this research tries to provide a concrete, reliable accomplishment, and the authors wish to apply the indicators to be a target for schools to raise students' ability in e-decision making competence.

According to the literature review and the Hermeneutics methodology, the researchers have revised the indicators into the final version, which includes seven competences in terms of information definition, information access, information assessment, information management, information conformity, information innovation and information dissemination.

The finding of the research shows the indicators have reached the experts' consistent level, and the reliability of each indicator's importance also has reached the superior level.

\section{Acknowledgements}

This research was supported by the Taiwan National Science Council (NSC 99-2511-S-254-001-MY3).

\section{References}

[1] R.T. Putnam, H. Borko, What do new views of knowledge and thinking have to say about research on teacher learning? Educational Researcher. 29 (2000) 4-15.

[2] P. Weill, J.W. Ross, IT Governance - How Top Performers Manage IT Decision Rights For Superior Results. Harvard Business School Press, 2004.

[3] A.J. Clark, It governance- determining who decides. Retrieved November 29,2009 from http://www.educause.edu/ecar/

[4] R.S. Albit, The what and who of information literacy and critical thinking in higher education, Libraries and the Academy. 7 (2007) 97-109. 
[5] R.M. Gagne, The Conditions of Learning and Theory of Instruction, Holt, Rinehart and Winston, New York, 1985.

[6] F. Hill-Briggs, Problem solving in diabetes self-management: A model of chronic illness self-management behavior, Annals of Behavioral Medicine. 25 (2003) 182-193.

[7] M.T. Huang, W.D. Chen, Problem Solving Skills, Science Education Monthly. 273 (2004) 21-41.

[8] J. Dewey, How we think, D. C. Heath, New York, 1933.

[9] R.Z. Hong, The Application of Hermeneutics methodology in policy making, Secondary Education. 48 (1997) 39-47. 